九州大学学術情報リポジトリ

Kyushu University Institutional Repository

\title{
State of Implementation of Environmental and Energy Policies Adopted by the Regional Governments in Japan
}

Moroga, Kana

Center for Science, Technology and Innovation Policy Studies, Kyushu University : Assistant Professor

Nagata, Akiya

Center for Science, Technology and Innovation Policy Studies, Kyushu University : Professor

Kuriyama, Yasutaka

Center for Science, Technology and Innovation Policy Studies, Kyushu University : Research Fellow

Kobayashi, Toshiya

Center for Science, Technology and Innovation Policy Studies, Kyushu University : Associate Professor

他

https://doi.org/10.5109/1544076

出版情報: Evergreen. 2 (2)，pp. 14-23，2015-09. Green Asia Education Center バージョン：

権利関係 : 


\title{
State of Implementation of Environmental and Energy Policies Adopted by the Regional Governments in Japan
}

\author{
Kana Moroga*, Akiya Nagata, Yasutaka Kuriyama, \\ Toshiya Kobayashi, Koichi Hasegawa \\ Center for Science, Technology and Innovation Policy Studies, Kyushu University, Japan \\ *Author to whom correspondence should be addressed, \\ E-mail: moroga@sti.kyushu-u.ac.jp
}

(Received August 12, 2015; accepted September 4, 2015)

\begin{abstract}
Our paper clarifies the actual state of implementation of environmental and energy policies, contents of policy measures, sources of information used to formulate policies, and links inside and outside of regions based on information collected through a questionnaire survey of regional administrative bodies nationwide. Subsequently, a text mining method was used to perform a correspondence analysis of project names and regional divisions to find the most frequently undertaken projects and whether or not differences exist between regions in this regard.
\end{abstract}

Keywords: environmental and energy policies, regional administrative bodies, information used to formulate policies.

\section{Introduction}

In this study, we conducted a questionnaire survey of municipalities, beginning in March 2013, called the "Basic Survey of Regional Science and Technology Innovation Policies." This survey was aimed at information gathering for developing the "Case-based Reasoning System for Regional Science and Technology Policies" and was intended to support officials in charge of formulating such policies ${ }^{1), 2), 4), \dagger}{ }^{\dagger}$. For the survey, a total of 1,789 regional administrative bodies-including 47 prefectures, 20 ordnance-designated cities, 41 core cities, and some other cities, towns, and villages, and special wards (23 wards of Tokyo; herein called "wards")-were selected. The survey had been conducted since March 2013, and questionnaires were returned by 1,789 regional administrative bodies at the end of August 2015, with 1,785 valid responses (four regional governments not responding).

The questionnaires surveyed the state of policy implementation and the basic elements employed in formation in relation to policies in the following fields: science and technology, environmental and energy, and design. This paper introduces part of the results from the basic survey of regional science and technology innovation policies, particularly concerning the state of efforts in environmental and energy policies. It also clarifies which information is deemed important by regional administrative bodies when formulating successful policies.

A fair number of studies analysing trends in Japanese environmental and energy policy have been performed heretofore ${ }^{3), 5), 6)}$. Much has been done already with respect to investigating and analysing specific regions. Nonetheless, relatively few studies are based on information collected through a survey of regional administrative bodies on a nationwide scale by way of clarifying the actual state of environmental and energy policy implementation, the contents of policy measures, sources of information used to formulate policies, and links inside and outside the regions. These points constitute the main focus of our study.

Section 2 presents an outline of the questionnaire survey, and Section 3, the final one, describes results from the text mining method used to perform a correspondence analysis on the most successful projects under environmental and energy policies in recent years. Finally, it also reveals what the most frequently conducted projects are and whether any regional differences exist in this regard or not.

\section{Outline of the questionnaire survey}

As mentioned previously, the questionnaire survey for the regional administrative bodies was designed to assess their efforts in tackling environmental and energy problems, as well as the efforts essential for sustained development of the regions. Our ultimate aim is to provide such regional administrative bodies with the information they require to formulate environmental and energy policies effectively. 


\subsection{State of the implementation of environmental and energy policies}

First, when asked if they had implemented environmental and energy policies in FY2012, out of the 1,789 regional administrative bodies surveyed, 647 $(36.2 \%)$ answered in the affirmative, $1,138(63.6 \%)$ said they had not, and 4 did not answer the question (see Fig. 1a). However, an examination of the implementation of environmental and energy policies (Fig. 1b) at the prefecture and ordnance-designated city level showed that more than $90 \%$ do implement such policies. By way of contrast, the percentage of implementation was below $20 \%$ for towns and villages, and slightly over $40 \%$ for other regional administrative bodies. This shows that the larger the administrative unit, the higher the percentage of implementation of the environmental and energy policies.

There are likely several reasons why environmental and energy policies are poorly implemented in many municipalities, but a significant one is that the related policies have been considered as a national-level responsibility, not a municipal; its implementation at the municipal level is also financially difficult. In addition, the PDCA (Plan-Do-Check-Act) cycle of the policy evaluation has not yet been performed enough, and environmental energy policy has not been well managed in many local governments.

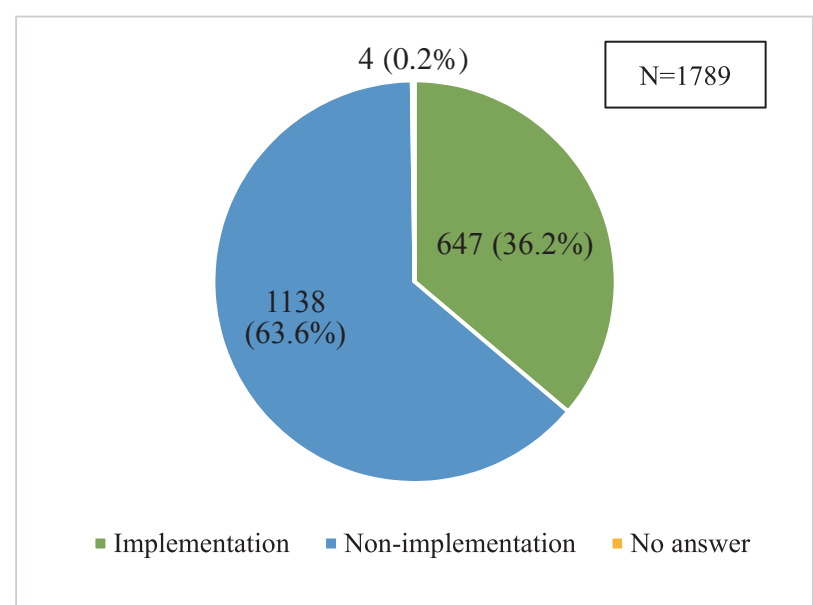

Fig. 1a. Implementation of environmental and energy policies at the local government level in Japan

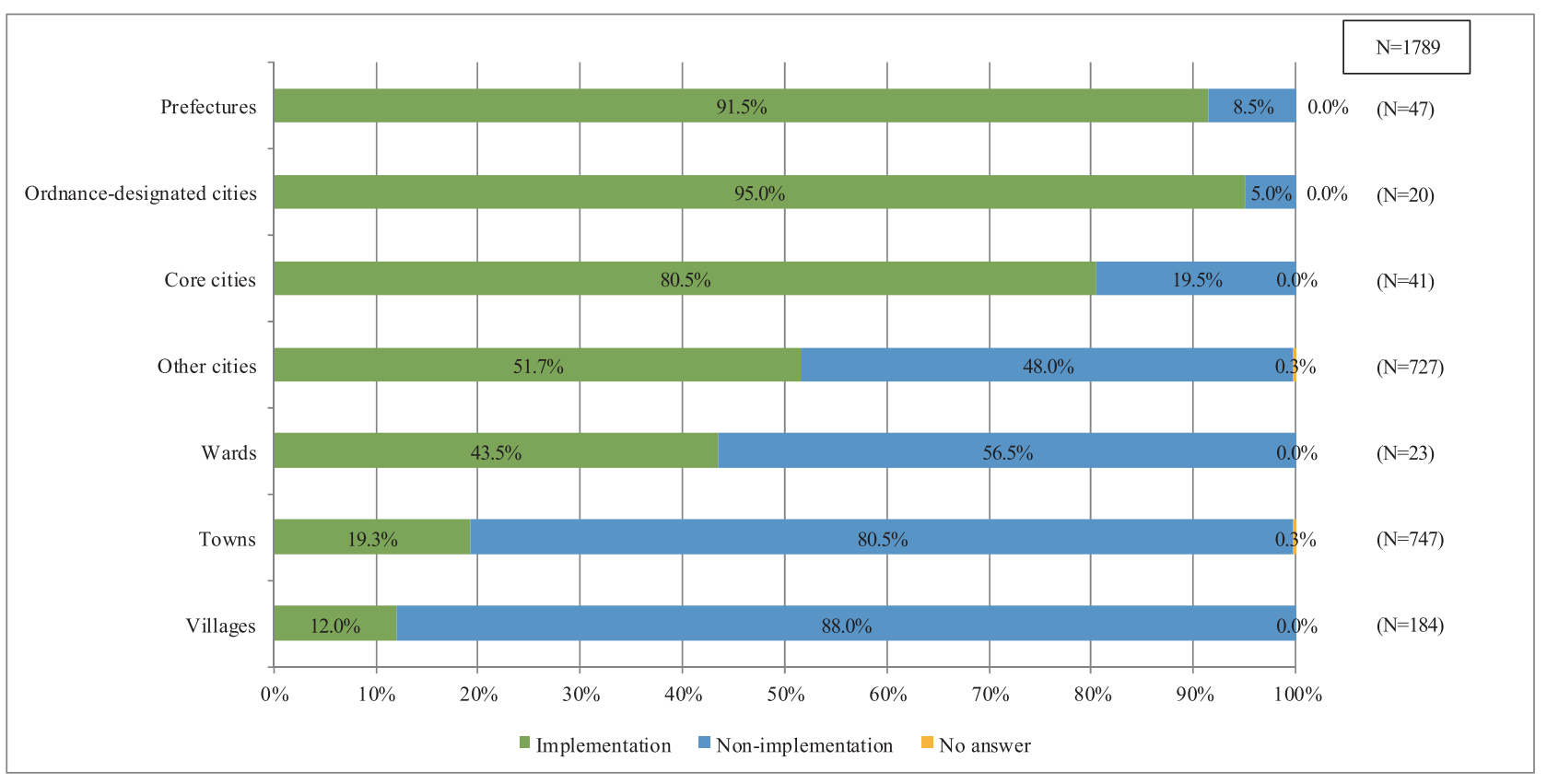

Fig. 1b. Implementation of environmental and energy policies according to category of local government

Almost all the regional administrative bodies (637 out of 647) that said they had implemented policies cited the names of some specific policy measures in progress at the time of the survey. These specific policy measures included "basic environmental plans" and "energy visions". Of the regional administrative bodies that provided the names of such policy measures, about $63 \%$ indicated the formulation of basic environmental plans.

When asked about the most successful projects in progress in the recent years, many of the regional administrative bodies mentioned solar power related projects, such as ones that involved subsidies for installing solar power systems. 


\subsection{Sources and types of basic information used to formulate environmental and energy policies}

The survey questions relating to the nature of information collected by the regional administrative bodies to formulate environmental and energy policies were as follows: What kind of information do officials at the regional administrative bodies refer to during the policy formulation process? What do they consider important when collecting basic information for policy formulation?

The survey provided a list of information sources from which they could select all those referred to in formulating the environmental and energy policies that were in progress at the time of the survey. The sources of information included "information provided by citizens and citizens groups", "consultants and think tanks", and "inspections, tours and interviews of the administrative organs and regional administrative bodies", among others. However, the most commonly used source of information by regional administrative bodies for policy formulation, chosen by a high percentage of the respondents, was "members of advisory councils and committees formed to enact policies" (see Fig. 2).

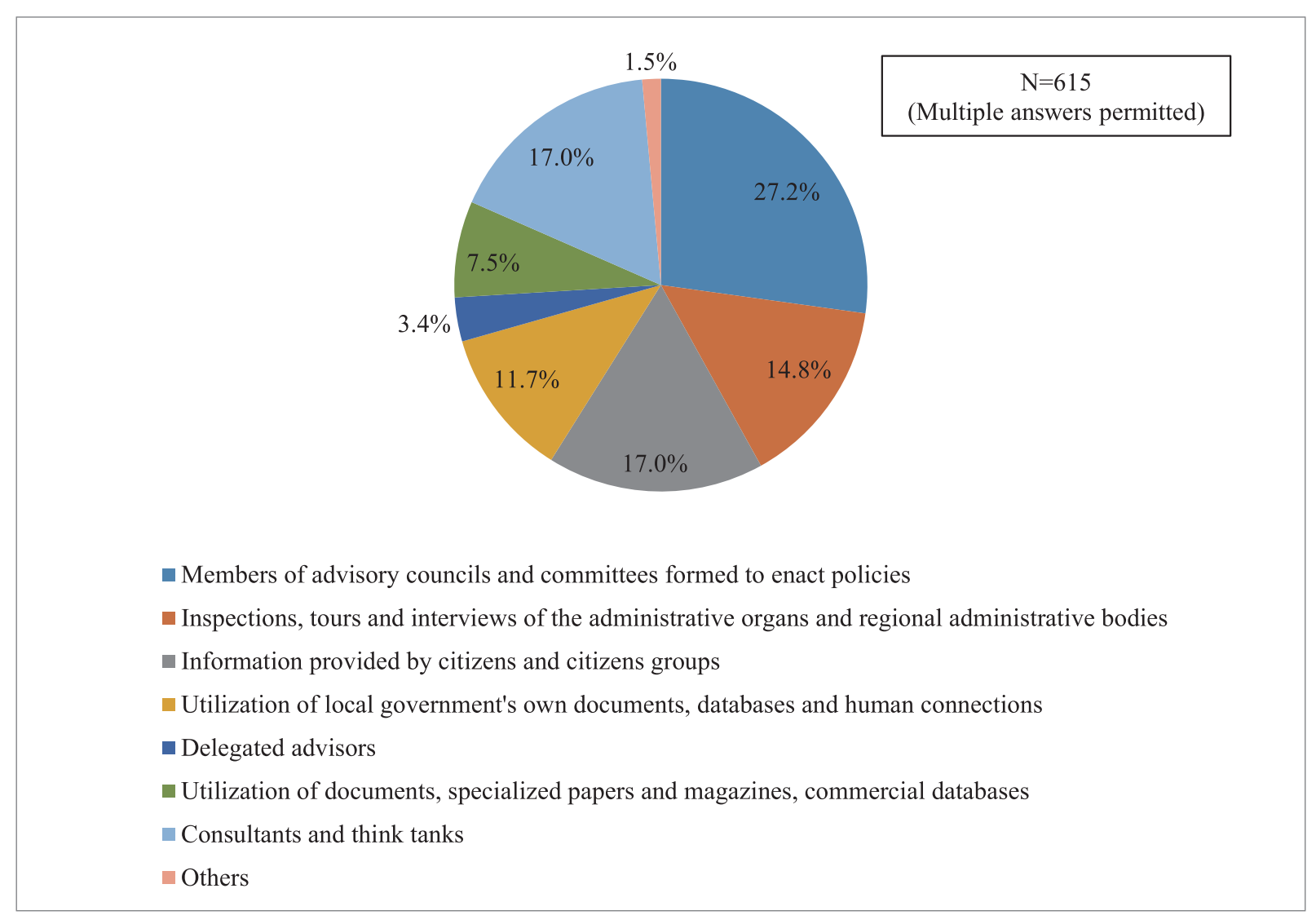

Fig. 2. Sources and types of basic information used to formulate environmental and energy policies (all local governments in Japan)

The basic information considered particularly important for formulating environmental and energy policy were "environment-related information from inside the region", "state of consciousness and actions of stake-holders", and "advanced cases inside and outside the region", among others. In cases wherein respondents cited only one source from among those available, a high percentage chose "environment-related information from inside the region" as what they considered most important when formulating policies (see Fig. 3a). An analysis of the results showed that most of the regional administrative bodies emphasised "environment-related information from inside the region" the most, followed by, for instance, in the ordnance-designated cities "state of consciousness and actions of stake-holders" and "advanced cases inside and outside the region" (see Fig. $3 b)$. Very few of the regional administrative bodies considered "environment-related information from outside the region", and none considered "record and estimation of air pollutant emission" to be important when formulating policies. 


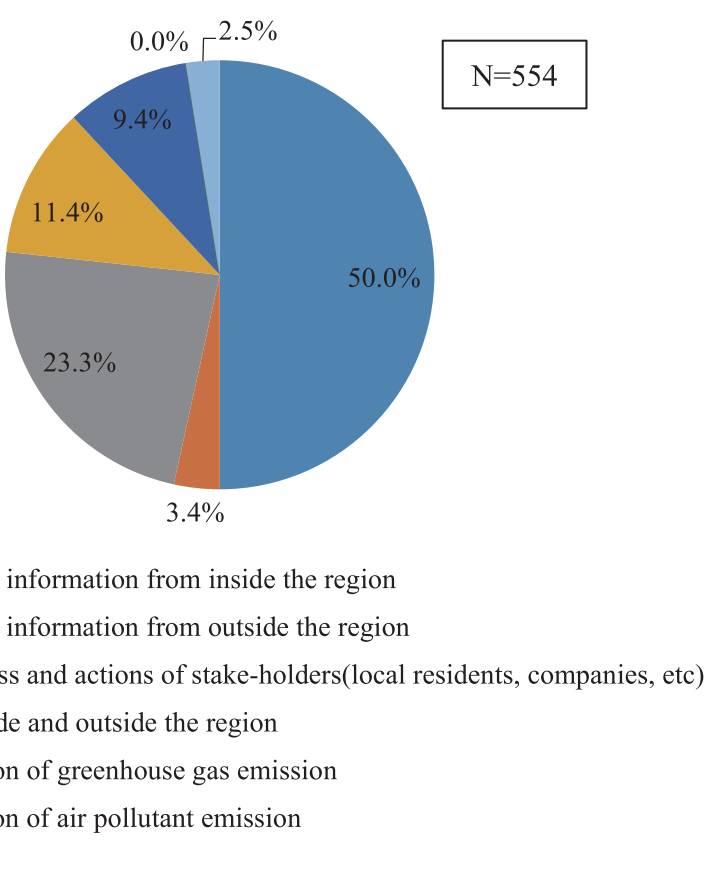

Fig. 3a. Basic information considered important for the formulation of environmental and energy policies (all local governments in Japan)

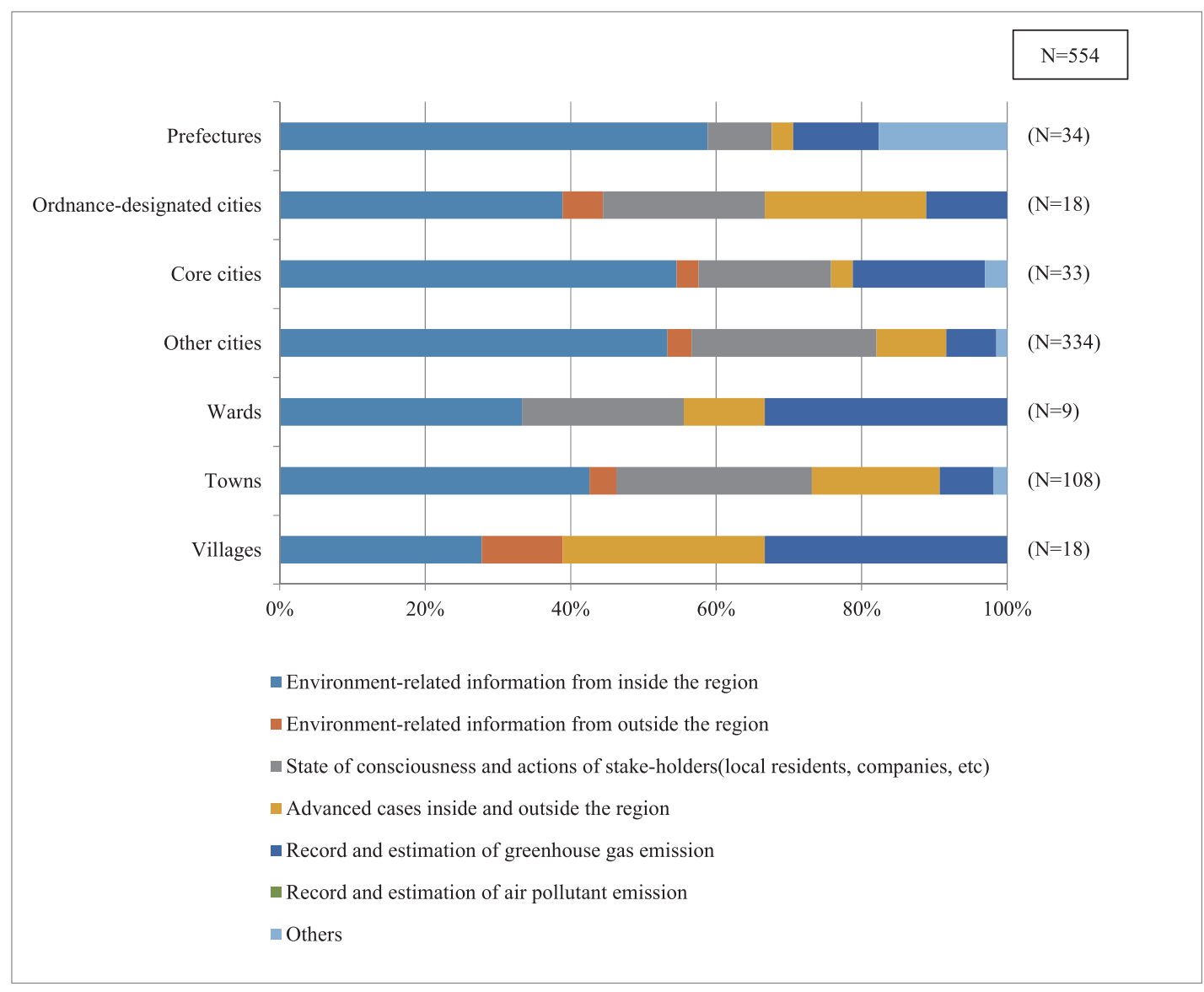

Fig. 3b. Basic information considered important for the formulation of environmental and energy policies (classified by category of local governments) 


\subsection{State of links and information exchanges with other regional administrative bodies}

In terms of links with other regional administrative bodies, Figure 4 shows that ordnance-designated cities aggressively form such links. These cities and special wards were also found to be quite active regarding information exchanges with domestic regional administrative bodies. However, the data shows that links and information exchanges with overseas regional administrative bodies are rare, and that even among the ordnance-designated cities, which actively form links and exchange information, only about $40 \%$ do so.

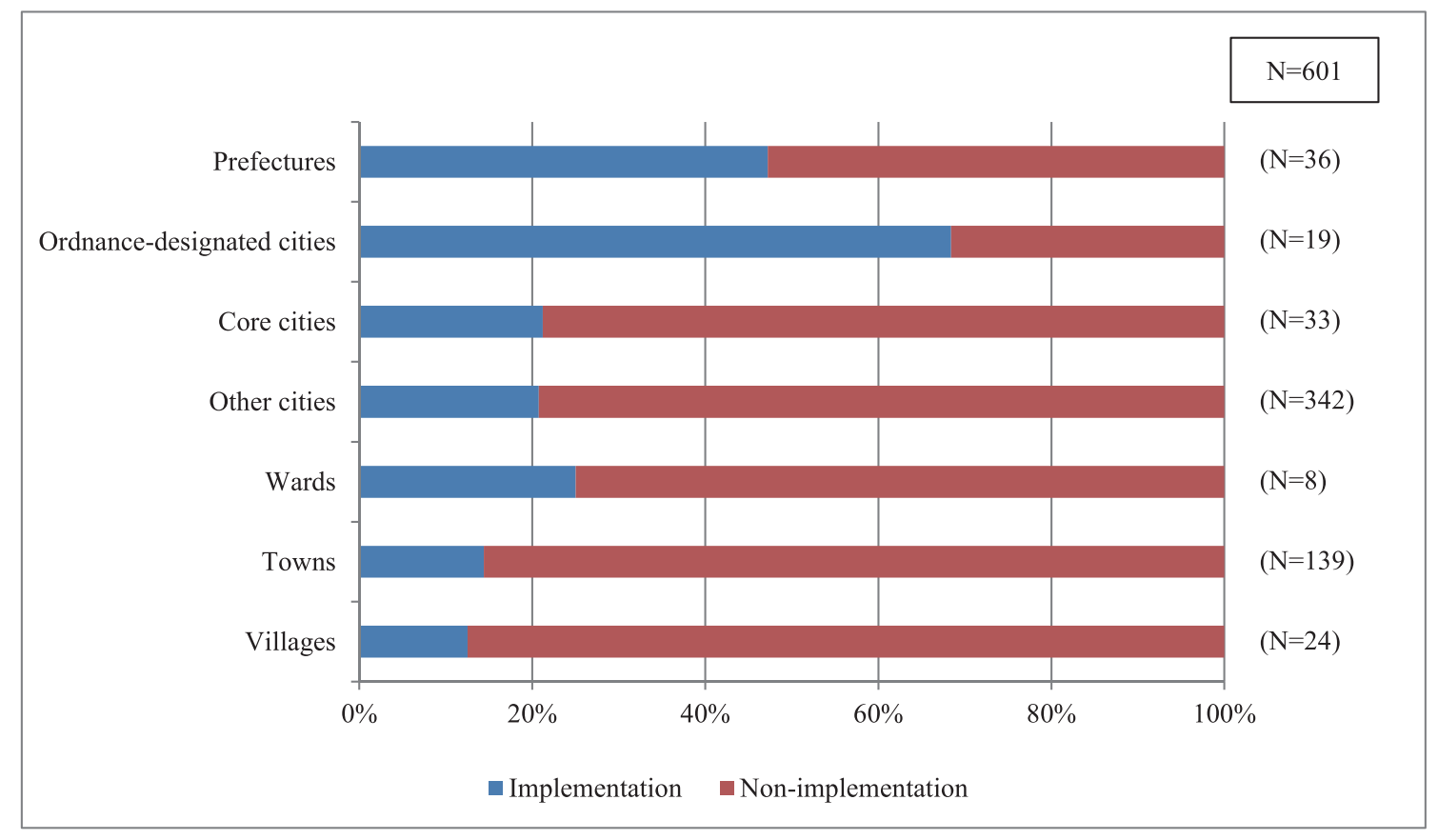

Fig. 4a. State of links with domestic regional administrative bodies

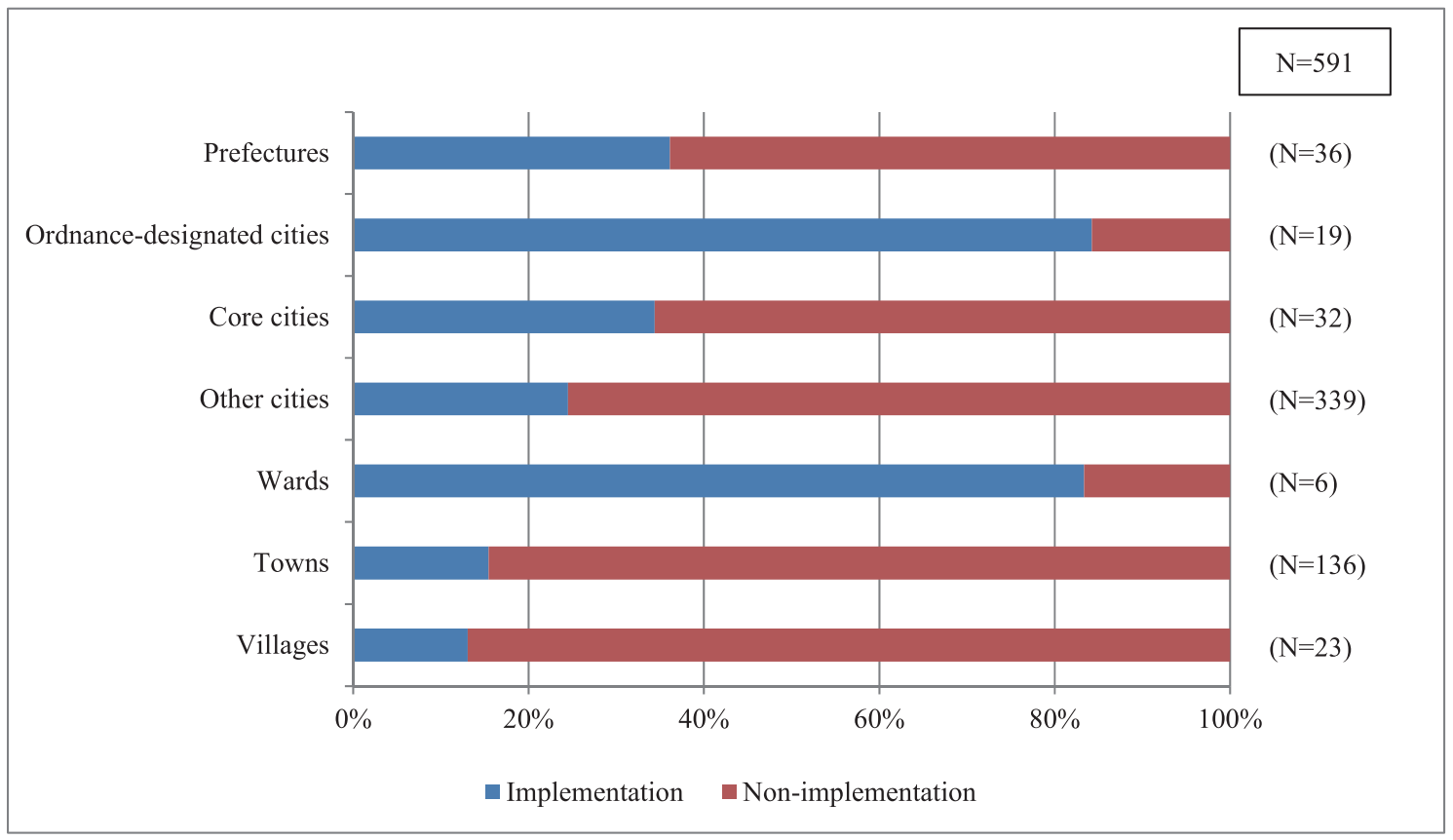

Fig. 4b. State of information exchanges with domestic regional administrative bodies 


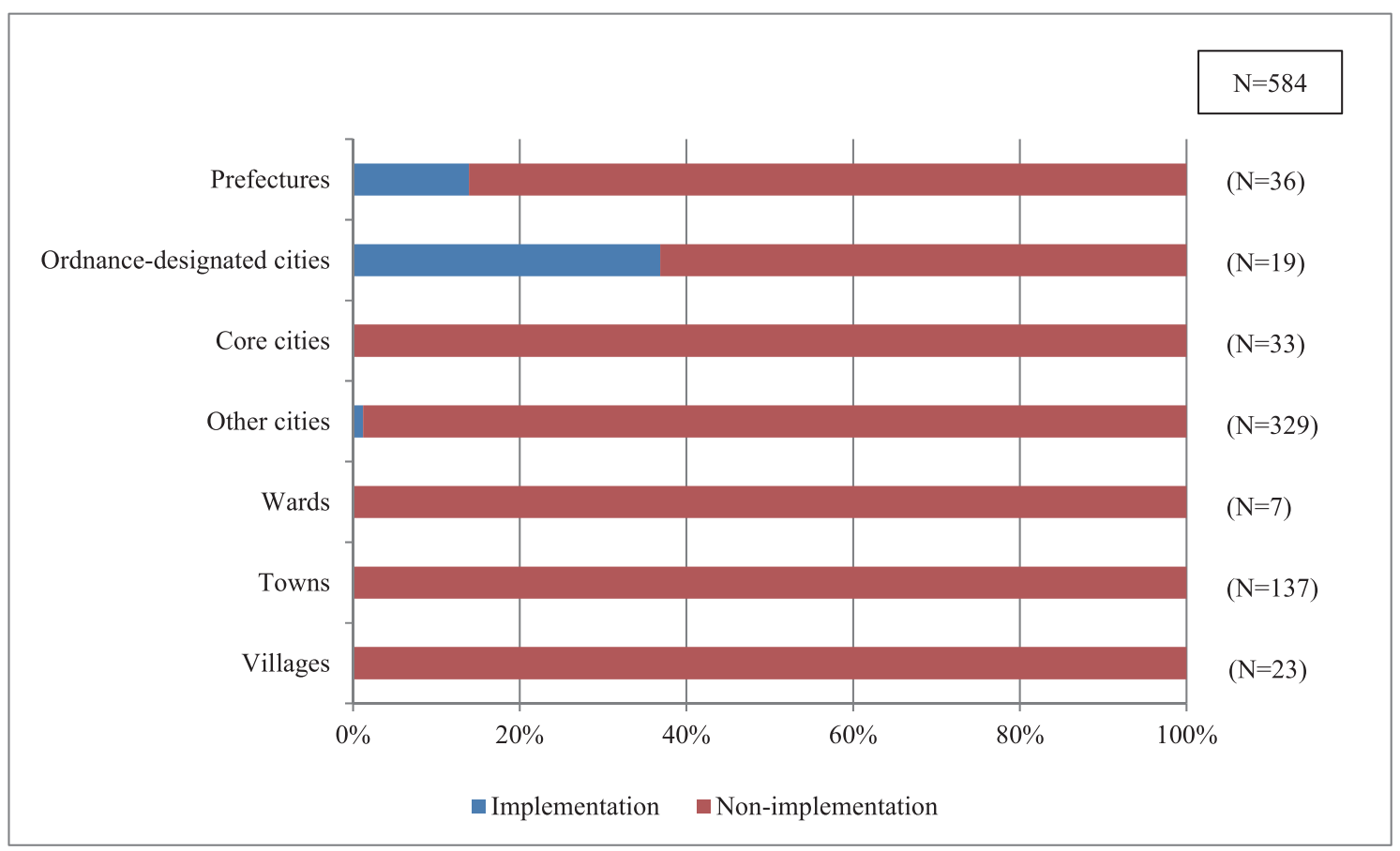

Fig. 4c. State of links with overseas regional administrative bodies

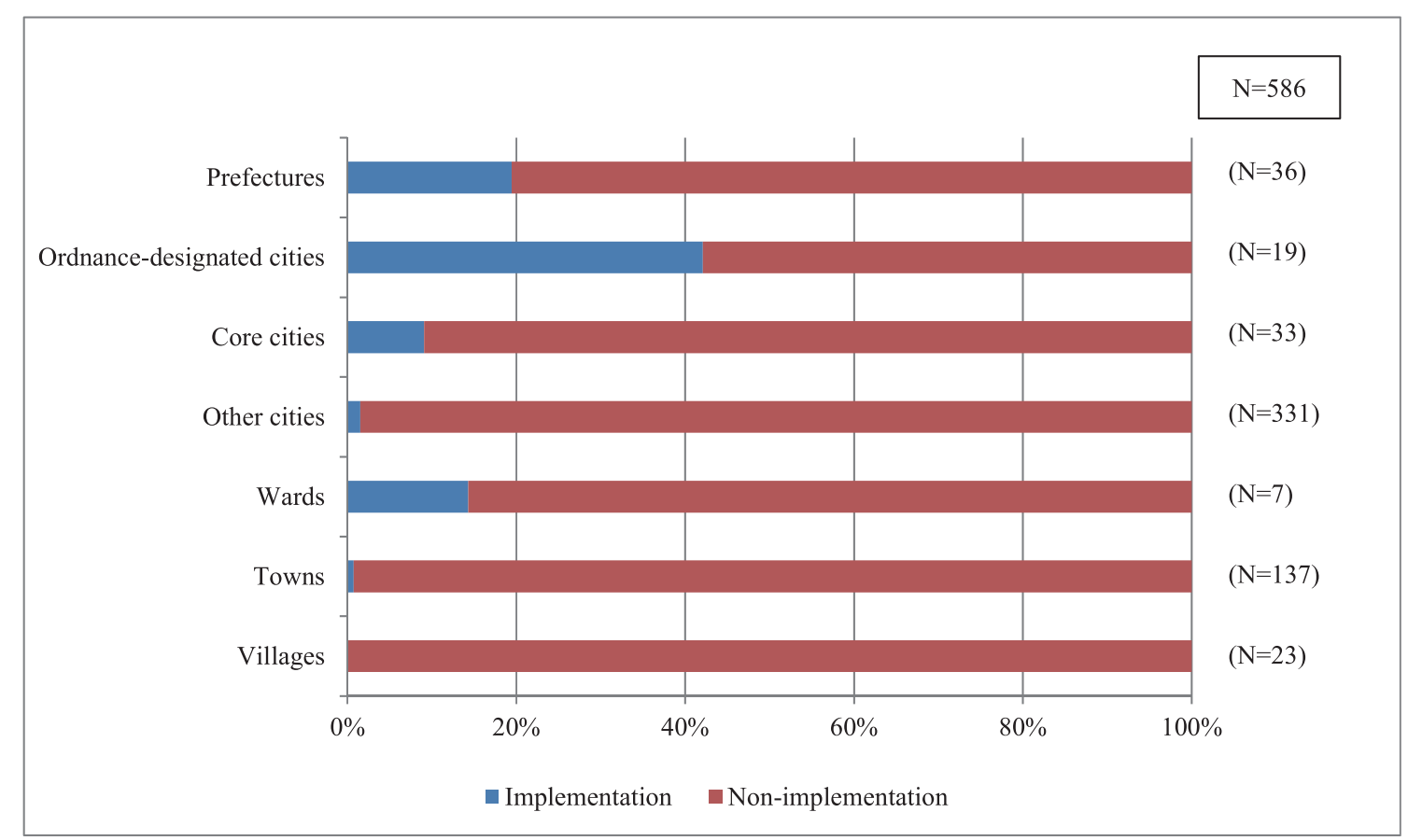

Fig. 4d. State of information exchanges with overseas regional administrative bodies

\subsection{Matters considered important for policy formation}

The survey provided a list of matters that might be considered important when formulating environmental and energy policies, requesting the respondents to select only one such matter. Overall, the results showed that "the future image of the region" was considered important when enacting policies (see Fig. 5). It was followed by "realising specific individual policy measures" and "numerical goals". For ordnance-designated cities, "realising specific individual policy measures" followed "the future image of the region" in terms of percentage. "Realising specific individual policy measures" showed a high percentage for the ordnance-designated cities most likely because they are regional administrative bodies with complete authority over their individual policy measures. 


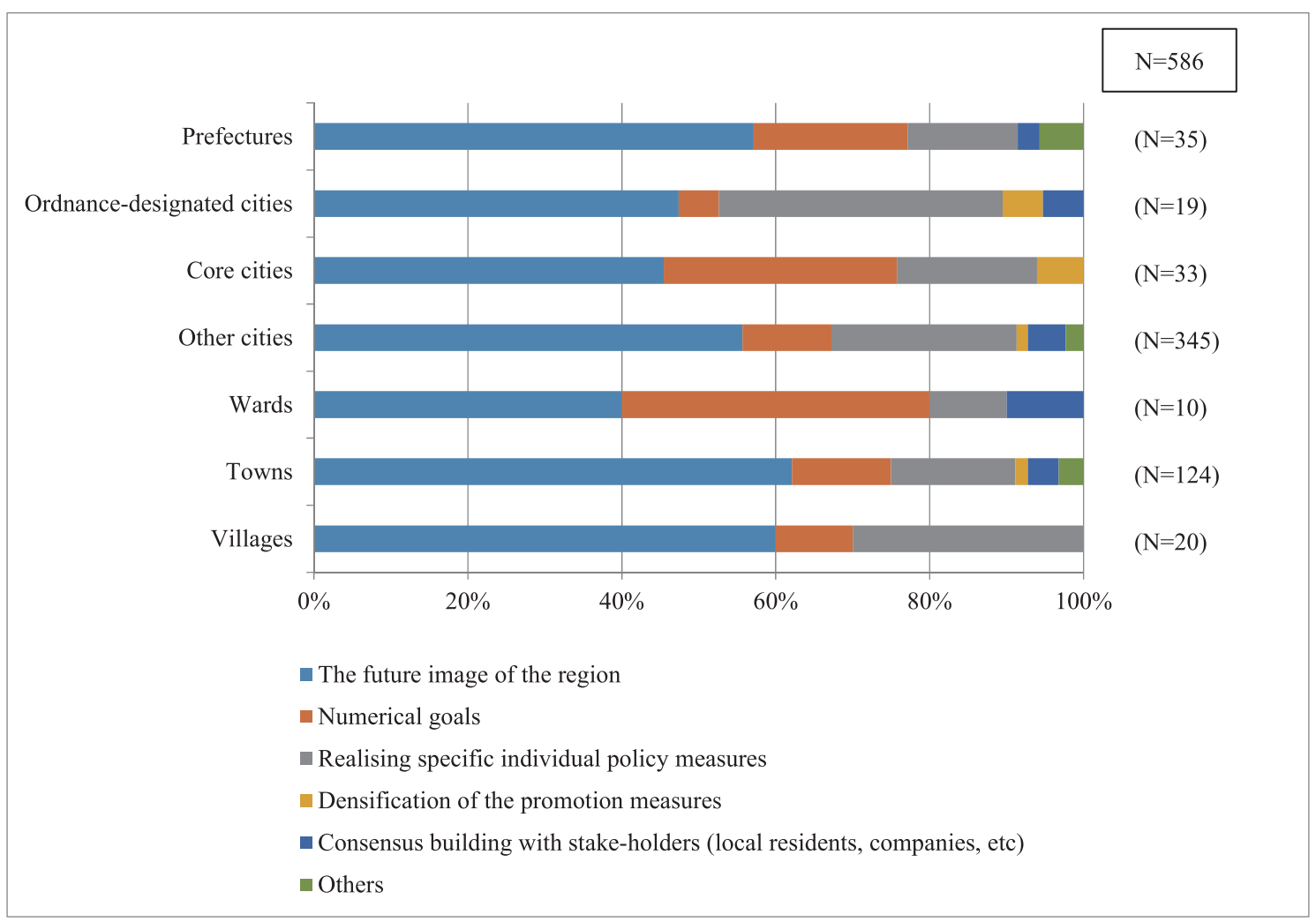

Fig. 5. Matters considered important for environmental and energy policy formation (classified by category of local governments)

\subsection{Factors behind the success of policies}

Finally, the questionnaire asked respondents to select up to three factors from a provided set which they thought were an important contribution to the success of the environmental and energy policies being implemented at the time of the survey. The factor considered to be the most important was "understanding and cooperation among stake-holders" (see Fig. 6). The next highest percentages were for "enlightenment activities through environmental education" and "policy incentives based on subsidies and preferential tax systems". Figure 6 also shows that the factors considered important for the success of policies by many regional administrative bodies did not include "measures based on science and technology", "links with universities, independent administrative agencies, and public research and development institutes", and "direct control by regulations and laws".

The case-based data presented here introduces the factors behind the success of environmental and energy policies currently enacted in advanced municipalities. However, for overcoming the various challenges related to environmental and energy problems in the future, we believe that the role of science and technology innovation, and encouraging links with universities, independent administrative agencies, and public research and development institutes will also become more important. Though "environment-related information from outside the region" and "advanced cases inside and outside the region" are types of information that can be useful when formulating policies, almost all regional administrative bodies face limitations in terms of cost and survey objects; therefore, it is assumed they cannot collect such information easily and have not been able to use them adequately. Another reason why regional administrative bodies have not been able to use information effectively that pertains to advanced cases is the lack of a system for sharing and using such policy information.

Because the local government environment (including the financial situation and the population scale) is different for each municipality, policies which are successful in some municipalities are not necessarily applicable to others. Therefore, local governments are expected to promote and improve their environmental and energy policies by carefully using the results of the analysis of success factors for policies in several local governments. 


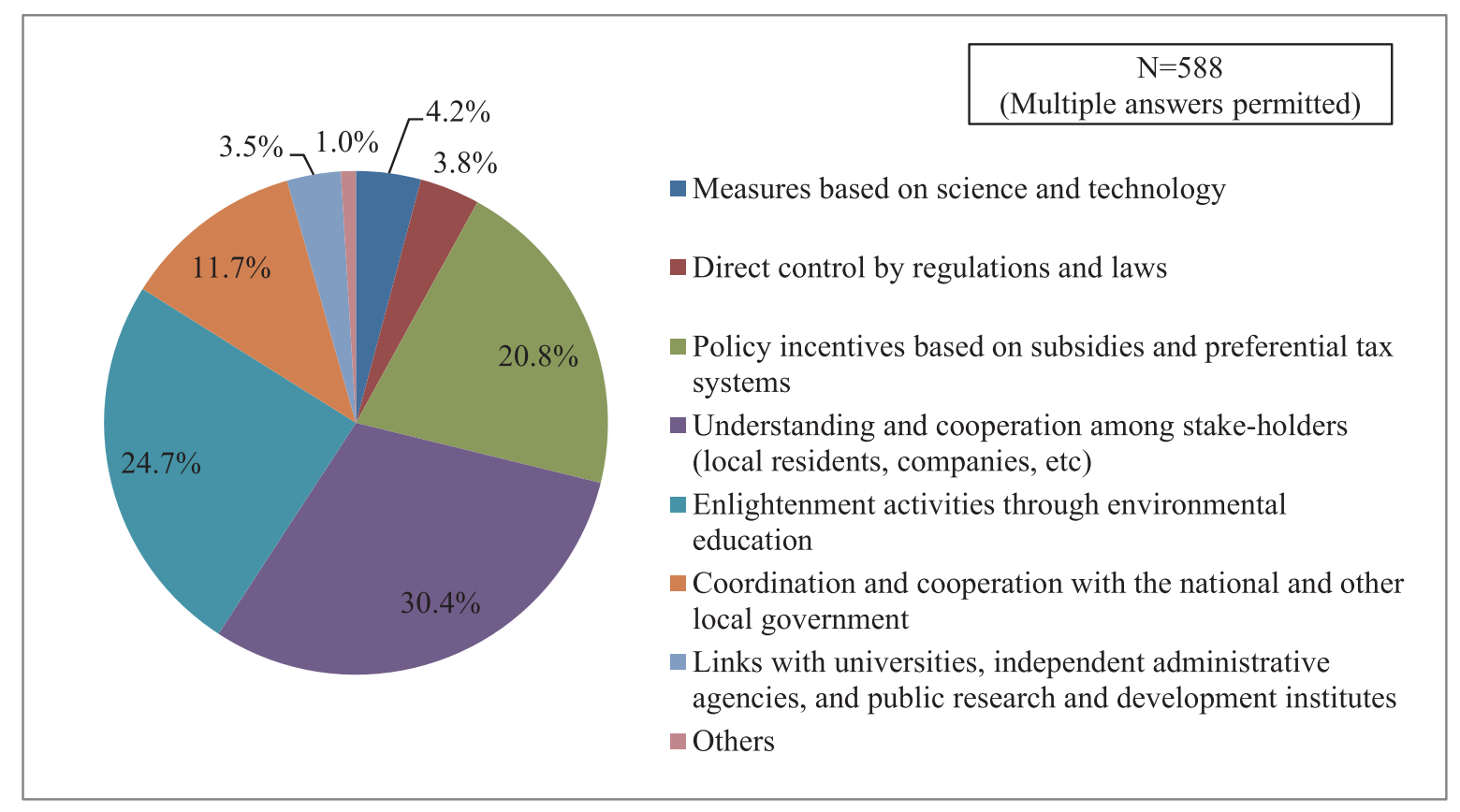

Fig. 6. Factors behind the success of environmental and energy policies (all local governments in Japan)

\section{Using a text-mining method to analyse data from the most successful projects undertaken in recent years}

This section provides a regional analysis of the characteristics of projects cited as the most successful in recent years in answer to survey questions such as the following: Which kind of projects are conducted most often? Are there regional differences between these projects? The data for these various projects was introduced into a text-mining tool (KH Coder) by project name to abstract important terms or key words, analyse the frequency at which they appeared, and plot the correlations. The $\mathrm{KH}$ Coder is free software used for statistical analysis of text data, such as from open-ended questions on surveys or for text mining.

Here, the correlation of the terms abstracted from the project names and regional divisions (8 divisions) was plotted, based on a correspondence analysis ${ }^{\dagger \dagger}$. The terms that appeared at least 7 times were abstracted.

First, our examination (see Table 1) shows that in FY2012, many regional administrative bodies implemented projects in the Kanto region, followed by the Chubu region. However, more than $50 \%$ of the regional administrative bodies in the Hokkaido, Shikoku, Kyushu, and Tohoku regions did not implement environmental and energy policies.

Next, Figure 7 shows the results of applying the text mining method. This method is applied to the text data from the answers to the question concerning the implementation of successful projects undertaken in recent years. The number of the respondents is largest in the Chubu region and second-largest in the Kanto region (see Table 2). The size of the circles (0) indicates the frequency of the appearance of each term; thus, the more often a project-related word appeared, the larger the circle. For instance, the circle for "solar power generation" is the largest, showing that there are many such projects. "Solar power generation" refers to solar power related projects other than "residential solar power" and "mega solar" (large-scale solar power generation with output higher than 1 megawatt).

The squares ( $\square$ ) represent the total number of projects implemented in each region. Further, a lesser distance between a square and a circle indicates a stronger correlation.

The results of the analysis reveal that the project type most often referred to as being the most successful in recent years was "solar power generation". Many of these projects have been implemented in the Kanto region, in particular. Whereas in regions such as Kyushu and Hokkaido, residential solar power generation projects are actively undertaken, mega solar projects are the most successful in the Kyushu division. In the Chubu area, there are many projects related to new energy, ecology, and global warming, while in the Tohoku region, many respondents indicated successful results in adopting biomass-related projects. "Subsidy" related projects were also considered to be successful in several regions.

In sum, while many regional administrative bodies stated that solar power generation related projects were the most successful among those implemented in recent years, regional differences existed, as expected. 
Table 1. State of implementation of environmental and energy policies (regional divisions)

\begin{tabular}{|l|r|}
\hline Geographical name & \multicolumn{2}{|c|}{$\begin{array}{c}\text { The number of local } \\
\text { governments } \\
\text { (Implementation) }\end{array}$} \\
\hline Hokkaido region & $\mathbf{4 7}$ \\
\hline Tohoku region & $\mathbf{7 6}$ \\
\hline Kanto region & $\mathbf{1 4 2}$ \\
\hline Chubu region & $\mathbf{1 2 9}$ \\
\hline Kinki region & $\mathbf{8 2}$ \\
\hline Chugoku region & $\mathbf{4 3}$ \\
\hline Shikoku region & $\mathbf{2 8}$ \\
\hline Kyushu region & $\mathbf{1 0 0}$ \\
\hline \multicolumn{1}{|c|}{ Total } & $\mathbf{6 4 7}$ \\
\hline
\end{tabular}

Table 2. State of implementation of "successful" projects related to environmental and energy policies (regional divisions)

\begin{tabular}{|l|r|}
\hline Geographical name & \multicolumn{2}{|c|}{$\begin{array}{c}\text { The number of local } \\
\text { governments (With } \\
\text { "successful" projects) }\end{array}$} \\
\hline Hokkaido region & $\mathbf{2 6}$ \\
\hline Tohoku region & $\mathbf{4 4}$ \\
\hline Kanto region & $\mathbf{7 6}$ \\
\hline Chubu region & $\mathbf{8 0}$ \\
\hline Kinki region & $\mathbf{5 1}$ \\
\hline Chugoku region & $\mathbf{2 5}$ \\
\hline Shikoku region & $\mathbf{9}$ \\
\hline Kyushu region & $\mathbf{4 3}$ \\
\hline \multicolumn{1}{|c|}{ Total } & 354 \\
\hline
\end{tabular}

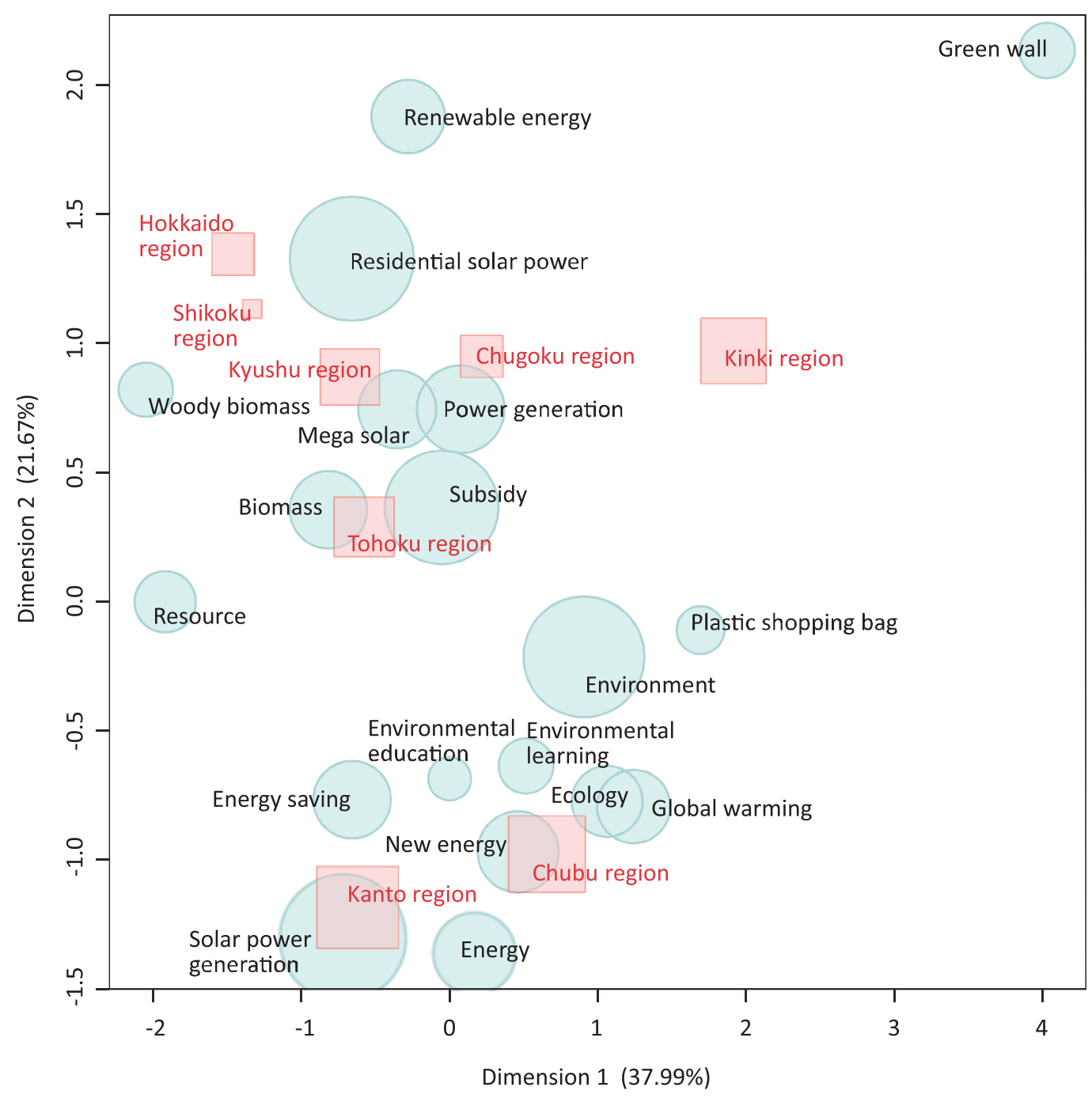

Fig. 7. Correspondence analysis of project names and regional divisions 


\section{Conclusions}

From information collected through a questionnaire survey of regional administrative bodies throughout Japan, our paper clarifies the actual state of the implementation of environmental and energy policies, the contents of policy measures, sources of information used to formulate policies, and links inside and outside the regions. The survey shows that only about $1 / 3$ of all regional administrative bodies currently implement environmental and energy policies. In order to realise a sustainable society, it will be necessary to make greater efforts to encourage undertakings at the level of regional administrative bodies.

A text mining method was used to perform a correspondence analysis of project names and regional divisions to reveal the most frequently undertaken projects and whether or not differences exist between regions in this regard. In recent years, the impact of the Great East Japan Earthquake and Feed-in Tariff Scheme for renewable energy has stimulated interest in renewable energies, and the FY2012 questionnaire survey conducted in this study showed that a high percentage of regional administrative bodies have opted for "solar power generation" as the most successful type of project in recent years.

Information and advanced cases related to environmental and energy policies of other regional administrative bodies can be the most useful kind of information in formulating policies; however, these are inadequately used by almost all the regional administrative bodies, indicating that a system for sharing information is needed.

\section{Note}

$\dagger$ This study presents part of the results of "Basic Survey of Regional Science, Technology, and Innovation Policies". This questionnaire survey of regional administrative bodies on a nationwide scale was conducted by the Center for Science, Technology, and Innovation Studies, Kyushu University, as part of the "Development of the Case-Based Reasoning System to Support Regional Science and Technology Policy" Project supported by Japan Science and Technology Agency (JST) under the "Strategic Basic Research Program". The purpose of the study is to collect data concerning regional science and technology policies and to build a database for construction of a decision-making support system for officials in charge of formulating policies. The database can be used by such officials to search for information on past cases, thus helping to resolve problems while formulating or implementing policies.

$\dagger \dagger$ For the regional divisions, refer to the Geographical Survey Institute.

\section{References}

1) A. Aamodt, E. Plaza, "Case-Based Reasoning: Foundational Issues, Methodological Variations, and System Approaches," Artificial Intelligence Communications, Vol.7:1, pp.39-59, (1994).

2) A. Nagata, T. Kobayashi, K. Hasegawa, K. Moroga, Y. Kuriyama, T. Ohno, "Development of the Case-Based Reasoning System for Regional Science and Technology Policy: An Interim Report," PICMET 2014 Proceedings, pp.135-139, (2014).

3) Central Research Institute of Electric Power Industry (CRIEPI), "Analysis of Environmental and Energy Policy Processes in the Local Governments in Japan Policy Development, Implementation Processes and Policy Diffusion," CRIEPI Research Report, (2006)

4) M. M. Richter, A. Aamodt, "Case-Based Reasoning Foundations," Knowledge Engineering Review, Vol. 20:3, pp.203-207, (2006).

5) T. Nakaguchi, N. Masuhara, Research Institute for Local Initiative of Environmental Policies (eds), Kankyo Jichitai Hakusho 2012-2013, Seikatsusha, (2012). (in Japanese)

6) T. Nakaguchi, Research Institute for Local Initiative of Environmental Policies (eds), Kankyo Jichitai Hakusho 2013-2014, Seikatsusha, (2013). (in Japanese) 